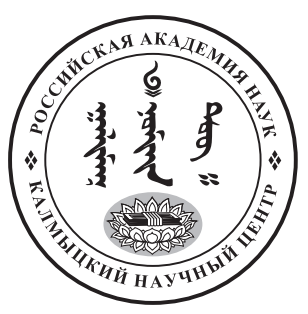

Published in the Russian Federation

Oriental Studies (Previous Name: Bulletin of the Kalmyk Institute

for Humanities of the Russian Academy of Sciences)

Has been issued as a journal since 2008

ISSN: 2619-0990; E-ISSN: 2619-1008

Vol. 14, Is. 5, pp. 1006-1015, 2021

Journal homepage: https://kigiran.elpub.ru

УДК / UDC 390 (571-52)+392.1 (571.52)

DOI: $10.22162 / 2619-0990-2021-57-5-1006-1015$

\title{
Функции и семантика свадебных головных уборов женщин как часть материальной и духовной культуры тувинцев
}

\author{
Елена Валерьевна Айыжы ${ }^{1}$, Роланда Биче-ооловна Ховальг² \\ ${ }^{1}$ Тувинский государственный университет (д. 36, ул. Ленина, 667000 Кызыл, \\ Российская Федерация) \\ кандидат исторических наук, доцент \\ iD 0000-0002-4289-3543. E-mail: aiygy@mail.ru
}

\author{
${ }^{2}$ Национальный музей им. «Алдан-Маадыр» Республики Тыва (д. 30, ул. Титова, 667000 Кызыл, \\ Российская Федерация) \\ главный хранитель
}

iD 0000-0002-6390-7406. E-mail: hovrol@mail.ru

\author{
(C) КалмНЦ РАН, 2021 \\ (C) Айыжы Е. В., Ховалыг Р. Б., 2021
}

\begin{abstract}
Аннотация. Введение. Целью данной статьи является исследование основных видов свадебных головных уборов тувинцев, играющих роль своеобразных знаков, обозначающих определенные этапы жизненного цикла. Материаль и методы. Основными источниками являются дореволюционные историко-этнографические сведения из фондов Национального музея им. «Алдан-Маадыр» Республики Тыва, а также полевые материалы авторов. В исследовании использован метод историзма, позволяющий рассматривать элементы культуры в развитии. Также применяются традиционные методы этнографии: сравнительно-типологический и метод полевого исследования. Результаты. В работе авторы проанализировали исторические, этнографические, фольклорные материалы. На основе анализа содержания традиционного свадебного обрядового комплекса тувинцев раскрываются символические качества свадебных головных уборов, их семиотика, свойства материалов изготовления и внешнего вида, прагматика и специфика локальных вариантов. Bblводы. Свадебная церемония в различных районах Тывы, несмотря на некоторые отличия по ряду параметров (наличию или отсутствию того или иного обряда, его функциональному значению), имеет общие основные структурно-типологические действия, такие как сватовство кудалаашкын, кудалай коор, смотрины дугдээшкин, свадьба куда-дой. Свадебная одежда тувинцев, проживающих в разных кожуунах Тывы, имеет общие устойчивые обрядовые действия и в то же время некоторые специфичные локальные особенности. В данной статье рассмотрены основные виды головных уборов, применявшихся во время свадебного комплекса.
\end{abstract}


Ключевые слова: свадебные головные уборы тувинцев, думаалай, баштангы, покрывало, ритуалы, обряд традиционная одежда, ритуальная одежда, свадебный обряд

Благодарность. Исследование проведено при финансовой поддержке гранта РФФИ «Трансформационные процессы в ономастике народов Центральной Азии: история и современность (на примере Тувы, Тофаларии, Калмыкии и Монголии» (№ 19-012-00073).

Для цитирования: Айыжы Е. В., Ховалыг Р. Б. Функции и семантика свадебных головных уборов женщин как часть материальной и духовной культуры тувинцев // Oriental Studies. 2021. T. 14 (5). C. 1006-1015. DOI: 10.22162/2619-0990-2021-57-5-1006-1015

\title{
Women's Wedding Headdresses in Tuvan Material and Spiritual Culture: Functions and Semantics
}

\author{
Elena V. Aiyzhy ${ }^{1}$, Rolanda B. Khovalyg ${ }^{2}$ \\ ${ }^{1}$ Tuvan State University (36, Lenin St., 667000 Kyzyl, Russian Federation) \\ Cand. Sc. (History), Associate Professor \\ iD 0000-0002-4289-3543. E-mail: aiygy@mail.ru \\ ${ }^{2}$ Aldan-Maadyr National Museum of the Tyva Republic (30, Titov St., 667000 Kyzyl, \\ Russian Federation) \\ Chief Custodian \\ iD 0000-0002-6390-7406. E-mail: hovrol@mail.ru \\ (C) KalmSC RAS, 2021 \\ (C) Aiyzhy E. V., Khovalyg R. B., 2021
}

\begin{abstract}
Introduction. The article aims to study key types of Tuvan women's wedding headdresses as signs associated with certain stages of the wedding ritual. Materials and methods. The research is mostly based on pre-revolutionary historical and ethnographic materials from the Aldan-Maadyr National Museum of Tuva and the authors' field data. The method of historicism employed for the analysis proves helpful in capturing the elements of culture in dynamics. The work also uses the comparative typological and field research methods that are traditional enough for ethnography studies. Results. The paper analyzes historical, ethnographic, and folklore materials to reveal the semantics of the Tuvan traditional wedding ritual and identify symbolism of wedding headdresses and their semiotics, materials used for their manufacture and decoration, local variants in terms of pragmatism and specific characteristics. Conclusions. The research indicates that despite some differences in several parameters (presence or absence of a particular rite or its functional significance), the traditional wedding ritual across different territories of Tuva is characterized by commonality of their basic structural and typological components, including matchmaking (Tuv. kudalaashkin and kudalai koor), bride show (dugdeeshkin), and wedding proper (kuda-doi). Accordingly, wedding clothes from different districts of Tuva have common ritual elements along with some specific local peculiarities. So, the paper focuses on key types of headdresses once used in wedding rites.

Keywords: wedding hats of Tuvans, dumalai, bashtang, bedspread, rituals, traditional clothes, ceremonial clothes, wedding ceremony

Acknowledgements. The reported study was funded by RFBR, project no. 19-012-00073 'Transformation Processes in Onomastics of Central Asian Peoples: Past and Present. A Case Study of Tuva, Tofalaria, Kalmykia and Mongolia'.

For citation: Aiyzhy E. V., Khovalyg R. B. Women's Wedding Headdresses in Tuvan Material and Spiritual Culture: Functions and Semantics. Oriental Studies. 2021. Vol. 14 (5): 1006-1015. (In Russ.). DOI: 10.22162/2619-0990-2021-57-5-1006-1015
\end{abstract}




\section{Введение}

Важной составляющей материального мира человечества всегда был и остается традиционный народный костюм. На протяжении столетий традиционная одежда выступала в качестве «зеркала культуры», в котором отражались не только внешние черты и аспекты бытовых условий жизни, особенности развития материальной культуры, но и важные периоды в жизни человека: детство, юность, зрелость, границы перехода из одной возрастной категории в другую, семейное положение, родство и похороны. Свадебный комплекс обрядов является неотъемлемой частью жизненного цикла любого этноса. Переход к зрелому возрасту характеризуется созданием семьи, приобретением нового статуса - уход из родного дома в другой; из одной родоплеменной группы в новую; из статуса парня, девушки - в мужа, жену и т. д. Во время проведения данного цикла обрядов огромную роль играет свадебный комплекс одежды жениха и невесты.

Характерной особенностью любой одежды обрядов жизненного цикла является семиотика, где каждый атрибут имеет определенное содержание и значение. Так, в традиционном обрядовом комплексе свадьба как у тувинцев, так и у других народов Центральной Азии играет важную роль в жизненном цикле.

Российский ученый-этнолог П. Г. Богатырев выделяет в традиционном народном костюме три основных вида: будничный, праздничный (торжественный) и обрядовый, при этом выделяя определенные специфические функции у каждого из них [Богатырев 1971: 297-366].

Включенный в ритуальную практику традиционный костюм языком символов и знаков отражал не только специфические особенности ролей участников свадьбы, но и наиболее существенные моменты самого свадебного обряда [Петров 2016: 110-114].

У невесты, кроме одежды, менялась прическа, а также украшения. По сведениям Л. П. Потапова, невесте полагалось надеть четыре серебряных перстня (следует отметить, что у бедняков они заменялись медны- ми), по два перстня на каждую руку (надевались они на средний и безымянный пальцы). Затем девушке надевали на обе руки по одному женскому серебряному браслету с каким-либо рисунком или орнаментом [Потапов 1969: 234].

Наряд замужней женщины был более нарядным, рукава и левая пола обшивались шелковыми и бархатными полосами, концы этой полы срезали. Следует обратить внимание, что ступенчатый срез имел разную интерпретацию у тувинцев (видимо, здесь играют роль локальные особенности родовых групп тувинцев). Для одних срез полы - это знак ухода девушки из родительского дома (отрезанная часть материи оставлялась у родителей). Для других такой срез обозначал знак, что в будущем не будет достойного мужчины, способного возглавить общество (в данном случае тувинского), поэтому такого украшения не должно быть на женской одежде. В любом случае эти примеры свидетельствуют о смысловом значении тувинской одежды.

Социальный статус также находил отражение в одежде. Так, В. П. Дьяконова отмечала, что если девушка была из богатой семьи, то к свадьбе у нее было до десяти а у бедных - только один-два тон. Если девушке из бедной семьи не могли приобрести шелковый свадебный тон, ей старались сшить хотя бы шелковый пояс (кур) [Дьяконова 1960: 234]. Скорее всего, здесь мы видим влияние монгольских порядков на тувинское общество, поскольку с XIII в. территория Урянхайского края входила в различные монгольские государственные образования. Этому имеется подтверждение: согласно принятому в 1640 г. «Их Цааз» («Великому Уложению»), у выходившей замуж богатой девушки должно быть 10 комплектов наплечной одежды [Их Цааз 1981: 64]. Кроме наплечной одежды, готовили также серебряные украшения, которые подвешивались к поясу.

\section{Свадебный комплекс}

Обрядовый цикл традиционной тувинской свадьбы до начала ХХ в. имел следующие этапы: кудалаашкын или кудалай көөр (сватовство) [Потапов 1969: 234], дугдээикин (смотрины), товун айтырар (договор о 
дне проведения свадьбы) - небольшой обряд, в котором участвуют только родители жениха и невесты, куда-дой (свадьба). При этом каждый этап имел, в свою очередь, определенную специфику в обрядовой одежде.

Своеобразным маркером социального статуса во время свадебного обряда служили и головной убор, и прическа невесты, которые определяли принадлежность к этнической и половозрастной группе. Головной убор невесты имел более знаковые функции в свадебном обряде, чем головной убор жениха. Смена его и обрядовые действия, которые проводили с волосами невесты, являлись одним из важных моментов свадебного ритуала.

\section{Сватовство}

Сватовство (кудалаашкьн) считается первым этапом свадебного цикла. В западной Туве, в частности в Бай-Тайгинском и Монгун-Тайгинском кожуунах, даже на современном этапе встречается традиция кудалай көөр (договоренность с младенческого возраста), когда родители договаривались о женитьбе своих детей еще в младенческом возрасте. Отцы мальчиков клали в колыбель маленьких девочек козий пух (чөөк), как знак, что она просватана. Подобную традицию также в некоторых местностях называли шай бузар (досл. 'разбить плитку чая’). Обряд проводился родителями уже позже, когда «жениху» и «невесте» исполнялось 7-8 или 10-12 лет, а по достижении ими 14-15 лет проходило сватовство. На современном этапе обряд шай бузар перешел в обряд прошения руки невесты келин айтырар (досл. 'испрашивать руки невесты') в несколько измененном виде: сегодня плиточный чай разбивают при обоюдной любви и согласии совершеннолетних молодоженов.

Обычай обручения «с колыбели» широко практиковался в прошлом у тюрков, родители договаривались о совместном будущем своих детей, когда те были еще младенцами. Если девушка или юноша по достижении соответствующего возраста отказывались от вступления в брак, то это могло рассматриваться, как позор для семьи, даже привести к кровной вражде. Данный обычай, также практиковавшийся в свадебной традиции тувинцев, свидетельствует о единстве истоков традиционной культуры тюркоязычных народов.

Для большинства тувинцев характерным был брак путем сватовства девочек, достигших 14-15-летнего возраста, - кудалаашкын [Потапов 1969: 234]. Сватать будущую невесту обычно приезжал отец жениха со своими родственниками, они привозили родителям невесты угощение: вареное мясо, сыр и, конечно, арагу (молочную водку), а также дарили шелковые кадаки (широкие ритуальные ленты).

В обряде кудалаашкын или кудалай көөр (сватовства) сами жених и невеста не принимали участие, поэтому одежда девушек-невест не имела особого отличия от повседневной. Девушка 14-15 лет носила наплечную одежду шыва тон с красной или разноцветной (с преобладанием красного цвета) полоской на подоле и головной убор довурзак. Головной убор во время сватовства был не обязателен.

По сведениям информантов ${ }^{1}$, в отличие от эдектиг тон (халата замужней женщины), шыва тон девушек не имел украшающих элементов. Но в работах С. И. Вайнштейна и М. О. Сиянбиль мы находим другие сведения о девичьем тон: на уровне прямоугольного среза (чирик) шла еще одна горизонтальная полоса из нашитой цветной ткани [Вайнштейн 1991: 158; Сиянбиль, Сиянбиль 2000: 18]. Халаты, украшенные подобным образом, носили преимущественно зажиточные женщины и девушки с наступлением половой зрелости. Ф. Я. Кон не исключал возможности, что появление разноцветных полос вдоль всего халата на высоте колен на подоле халатов у девушек старше 14 лет связано с началом у них менструаций [Вайнштейн 1991: 158].

Если родители девочки были согласны выдать ее замуж после сватовства, то мать невесты брала поднесенные сватом кадаки и клала их в шкатулку дочери (хомду хааржак) [Потапов 1969: 235].

\section{Смотрины}

Окончательное согласие и договоренность о сроке свадьбы достигались и закреплялись во время второго специального

${ }^{1}$ Куулар Л. К., Байкара Е. Ш. - информанты, консультанты, старейшие сотрудники Национального музея им. «Алдан-Маадыр» Республики Тыва. 
приезда родственников жениха в дом родителей невесты, на этот раз уже с самим женихом. Этот свадебный цикл называется дугдээшкин (смотрины).

По сведениям информанта, когда мать просватанной девушки во время обряда дугдээшкин делила волосы на две части, заплетала в косы и крепила к ним парные накосные украшения салбактар, это означало приобретение девушкой нового статуса невесты и символизировало появление в ее жизни спутника ${ }^{1}$. В Монгун-Тайге во время обряда дугдээикин между двумя косами невесты крепили женское накосное украшение чавага [Потапов 1969: 237], которое в большинстве кожуунов Тувы женщины впервые начинали носить только во время свадьбы.

После обряда дүгдээшкин до свадьбы девушка носила головной убор с длинной кистью маак (или чалаа) из красных шелковых нитей, которую крепили на макушку шапки, а также на головной убор невесты нашивали более широкую кайму хаш красного цвета. Этот головной убор символизировал новый статус девушки-невесты.

Невеста, кроме прически, должна была сменить свои девичьи украшения - колечки чүстүк, браслеты билектээш и серьги сыргалар - на женские [Потапов 1969: 239]. Полагалось надеть четыре серебряных перстня с большой накладкой-пластиной, по два перстня на каждую руку (на средний и безымянный пальцы). У бедных людей обычно эти перстни были медными. Кроме того, невесте надевали на обе руки по одному серебряному браслету с каким-либо рисунком, в отличие от совершенно гладких девичьих браслетов. Девичьи серьги, простые и круглые, также заменялись женскими - крупными, с длинными подвесками.

После дүгдээшкин для невесты заказывали еще подвески-бляшки дергилер, игольницы ховул, огнива из серебра или меди, которые входили в состав поясных украшений замужней женщины. Стоимость всех этих не очень затейливых украшений равнялась цене хорошего коня, поэтому для многих семей приобретение их своими силами было затруднительно [Потапов 1969: 239]. Поэтому, кроме родственников невесты, в

${ }^{1}$ Куулар Л. К. - информант, этнограф, сотрудник Национального музея им. «Алдан-Маадыр» Республики Тыва, 1955 г. p. расходах по изготовлению украшений иногда принимал участие и жених, который отдавал, например, свои собственные украшения для переделки на украшения своей будущей жены. Следует обратить внимание, что раньше у тувинцев кольца и серьги носили также мужчины и юноши. Как женатые, так и холостые мужчины носили круглые (медные, серебряные и золотые) кольца на большом и указательном пальцах, также могли носить еще и серьги в ушах. Серьги были круглыми из серебра, маленькими в виде колечек и также гладкими, без всяких рисунков и подвесок [Потапов 1969: 239-240].

После обряда дугдээшкин родители невесты начинали готовиться к свадьбе. Комплектование имущества для невесты называется по-тувински бээр уругнун херексели [Потапов 1969: 237].

\section{Свадьба}

Третий и заключительный этап свадебного цикла назывался куда-дой. Содержание данного обряда заключалось в переезде невесты в аал жениха и организации свадебного пира, который проводили на новом местожительстве молодых. Начинался этот заключительный этап с переезда невесты, что называлось по-тувински уругну алыр (принятие девушки) [Потапов 1969: 240].

Невеста надевала новую, специфическую для замужней женщины одежду, начиная с нательной. Ее новый эдектиг тон имел более широкие цветные каймы на подоле. На ней были надеты серебряные/медные украшения: серьги, кольца, перстни, браслеты, поясные, накосные украшения. Отъезжая из своего родного дома в дом жениха, невеста надевала особые свадебные головные уборы думаалай и баштаңзгы [Вайнштейн 1991: 171].

Думаалай - тувинское свадебное покрывало (широкое четырехугольное полотнище с отверстиями для глаз), которым молодая, прибыв в юрту мужа, прикрывала в первые дни лицо от старших родственников мужа. Второй свадебный головной убор баштанцгы - накидывали поверх думаалай. В большинстве кожуунов после свадьбы невеста снимала думаалай и носила на голове баштанцьы. В Монгун-Тайге на второй день после свадьбы невеста снимала дуумалай и надевала кожагар бөрт - островерхую праздничную шапку. 
У многих народов наиболее сакральной частью одеяния невесты является свадебное покрывало, у тувинцев - думаалай. Во время укрывания покрывалом происходила символическая утрата невестой девичьего статуса, что являлось необходимым условием для её перехода в разряд замужних женщин [Петров 2016: 112].

\section{Свадебные головные уборы и обрядо- вые действа}

На основе обобщения литературы и архивных источников можно подчеркнуть, что покрывало невесты у разных народов, с одной стороны, выполняло функцию оберега, потому что закрывание лица невесты, по народным представлениям, являлось одним из важнейших средств защиты от сглаза и порчи, а с другой - являлось маркером, свидетельствующим о переходе девушки из одной социально-возрастной группы в другую, из категории невест в категорию замужних женщин [Петров 2016: 110-114].

Данный переход осуществлялся в процессе особого обряда, когда с невесты снимали покрывало и девичью шапку, меняли прическу и облачали в женский головной убор. У тувинцев женщины после снятия думаалай оставляли на голове женский головной убор баштангы.

Подобные тувинскому думаалай, свадебные головные уборы существовали до начала XX в. у разных народов, например у киргизов шөкүле [Антипина 1962: 226-227], у чувашей пёркенче́к [Петров 2016: 110 114], у турков дувак, у казахов желек. Пв́ркенчغ̇к чувашей представляет собой сшитое из нескольких полос тонкого и белого домотканого холста большое прямоугольное полотнище, которое закрывало не только голову и лицо, но и всю фигуру невесты. Киргизский шөкүле, имеющий некоторое сходство с казахским желек, состоял из конической шапочки с наушниками и длинной треугольной лопасти, спускавшейся на спину. Его украшали сеткой из коралловых бус. Лишь с середины XIX в. этот убор шөкүле стал свадебным [Антипина 1962: 250]. Возможно, что и тувинский баштаңңгы был раньше головным убором замужних женщин, став лишь позднее только свадебной принадлежностью, так как тувинские женщины надевали его после свадьбы в праздничные, иногда и в будничные дни.
Подлинное свадебное покрывало думаалай из коллекции ученого-исследователя Ф. Я. Кона, находящееся в фондах Российского этнографического музея (далее РЭМ), представляет собой четырехугольное полотнище из красной ткани длиной 1,8 м, шириной 1,34 м. К верхнему его краю пришит овальный кусок зеленовато-голубой ткани, надеваемой на голову. Он собран на вздержках, концы их соединены и образуют небольшое округлое отверстие, из которого расходятся складки.

Думаалай шили из ткани красного, зеленого, синего, голубого и белого цветов [Вайнштейн 1991: 171]. В фондах Национального музея Республики Тыва имеется один экземпляр думаалай, сшитый из белой шелковой ткани, украшенный бахромой из оранжевого и желтого бисера.

Женский свадебный головной убор баштаңзгы в виде накидки на голову и плечи длиной до талии выкраивался из цветной ткани [Вайнштейн 1991: 172]. В качестве украшений к краям баштангы пришивали бусы, монеты, раковины каури, а также просверленные резцы марала. В свадебные дни баштангы носили поверх думаалай, в дальнейшем надевали по праздникам, нередко и в будни уже без думаалай. Он состоит из трех предметов: свадебное покрывало $\partial y$ маалай, которое надевается на голову в первую очередь, потом баштангы, состоящий из двух предметов - широкого плата, опускающегося на спину и плечи и маленькой круглой шапочки с плоским верхом, надеваемой поверх этого платка. Платок баштан$2 b l$ на вздержке, к которой с боков и затылка пришит покров, опускающийся на плечи и спину. Думаалай сшит из белой шелковой ткани прямоугольной формы, края которой окантованы разноцветной тесьмой и бахромой из бисера.

Богато украшенные баштаңзгы и думаалай хранили и передавали из поколения в поколение, как несомненный признак богатства. Ф. Я. Кон в своих дневниковых записях отметил, что во время посещения юрты тувинцев хозяйка показала свою баштанга и тумалай. Оба этих головных убора убраны такими крупными кораллами, что сотни рублей стоят. Затем показали пару серебряных серег с такими же крупными кораллами. 
Исследователь Е. К. Яковлев, описывая тувинскую свадьбу, обратил внимание, что во время самой свадьбы родичи невесты привозят юрту с полным хозяйственным обиходом, которая ставится сначала подле юрты родителей жениха. Молодежь с женихом и невестой устраивают пир в новой юрте, а пожилые родственники молодых пируют в юрте отца жениха. Невеста садится рядом со свекровью и закрывается брачной вуалью думаалай, пока свекор не сдернет ее с головы [Традиционная культура 2003: 58]. На второй день после свадьбы невеста уже снимала и укладывала думаалай в свой ящик-сундук хомду хааржак, где она и хранилась в течение всей жизни замужней женщины.

Во время экспедиционных работ авторы неоднократно были свидетелями этих традиций - обычай прикрывания лица невесты свадебным покрывалом думаалай.

Очень интересную характеристику дал Л. П. Потапов на основании четырех экземпляров, хранящихся в коллекциях, приобретенных в начале XX в. Ф. Я. Коном в различных районах Тувы [Потапов 1969: 240-241]. Головной убор невесты, который Ф. Я. Кон называет фатой, шили из одноцветного красного или вишневого шелка. Он состоит из легкой, небольшой и неглубокой шапочки круглой формы, сшитой из синего, голубого и зеленого шелка, на вздержке, к которой с боков и затылка пришит покров (длина от 95 до 134 см) из двух полос красного или вишневого шелка, он покрывает плечи и спину невесты. Накидка обшита по краям полосой шелковой ткани того же цвета, что и шапочка или колпачок покрывала. Украшение «фаты» сосредоточено у колпачка и состоит из околыша, сшитого из меха горностая (или другого ценного меха), иногда с лапками и хвостиками. К меховой опушке на черных шелковых шнурках пришиты кисточки из шелковых ниток разных цветов, с разноцветными бусинками, а на передней стороне над лицом висят снизки от бус, без кисточек. В других экземплярах иногда вместо меха шапочка обшита околышем из красной полоски шелка, к которому пришиты подвески из цветных бусинок, китайских медных монеток и пуговиц. Судя по данному описанию, это одна из разновидностей думаалай, в котором лицо прикрывается только снизками бус.
В фондах Национального музея Республики Тыва хранится вышеуказанный один экземпляр думаалай, полностью прикрывавший лицо невесты, в виде прямоугольного платка с дырками для глаз, сшитый Т. Н. Хертек.

Рассмотрим описание баштаңъгы, составленное Л. П. Потаповым на основании образцов, увезенных Ф. Я. Коном в самом начале XX в. в РЭМ: «Баштаңгы даже во времена путешествия Ф. Я. Кона считался у тувинцев старинным головным убором. Он представляет собой большой капюшон, сшитый из красной шелковой материи, с несколько удлиненной частью, ниспадающей на спину. Шили его из двух продольных половин, покрой которых при соединении в плане имеет почти форму круга, нижняя половина которого немного удлинена и суживается, образуя овально-закругленный выступ, который при надевании баштангы лежит на спине.

Наголовная часть капюшона небольшая, едва спускающаяся на лоб. На верхушке капюшона (приходящейся при надевании на темя) маленькое круглое отверстие, прикрываемое теперь небольшой широкой лентой голубого цвета, идущей от лба через голову и опускающейся свободно на затылок» [Потапов 1969: 252].

Объяснить назначение этого отверстия не удалось даже Л. П. Потапову, который проводил научные экспедиции в Туву в конце 50-х гг. ХХ в.

Но предположение о содержании значения отверстия имеется: во многих традиционных культурах большое значение придавалось макушке или темени женщины. Именно поэтому девичьи шапки и женские свадебные уборы нередко имели сверху отверстие, накладки либо яркую вышивку. Такие отверстия имеются у головного убора, идентичного с баштаңзды из коллекции Ф. Я. Кона.

Только 1-2 экземпляра подлинных свадебных уборов сохранились в Национальном музее Республики Тыва и РЭМ. Описание одного из них - баштангы - было опубликовано в работе «Очерки этнографии тувинцев левобережья Хемчика» Тувинской комплексной археолого-этнографической экспедиции Института этнографии АН СССР (ныне - Институт этнологии и антропологии имени Н. Н. Миклухо-Ма- 
клая РАН) в 1966 г.: «Длина наибольшей, ниспадающей на спину части баштангы в описываемом экземпляре 75 см. Характерной его особенностью являются его отлитые из свинца украшения - маленькие пластинчатые бляшки, оканчивающиеся шариком. Этими бляшками обшиты сплошь все края баштангы, выше которых идут, также сплошной обшивкой, впритык друг к другу, два ряда красных бус» [Потапов 1969: 252]. Поскольку данный экземпляр баштангы был обнаружен в местности реки Хемчик, можно сделать вывод, что он был характерен для хемчикских женщин. Идентичный и единственный подлинный экземпляр свадебного головного убора баштаңъгы имеется в фондах Национального музея Республики Тыва.

В работе другого ученого Г. Е. ГруммГржимайло «Западная Монголия и Урянхайский край» мы находим подтверждение тому, что после свадьбы женщины в качестве повседневного головного убора носили баштангы. Он отметил, что летом же чаще всего женщины заменяют шапку платком русского изделия или особым головным убором баштанга, который представляет собой кусок красной шерстяной ткани величиной около 3/4 квадратного аршина, надеваемый таким образом, чтобы одним своим краем закругленным и подрубленным, он нависал надо лбом, защищая глаза от солнца, а тремя другими свободно спускался на плечи и спину [Грумм-Гржимайло 2003: 109].

В некоторых местностях после снятия на свадьбе думаалай женщины вместо баштангы носили праздничную шапку кожагар бөрт (маактыг бөрт), характерную для богатых скотоводов западных районов, причем такую шапку носили и мужчины, и женщины [Вайнштейн 1991: 167].

Она имела простеганную высокую коническую тулью шаалынчын, обшитую цветной тканью. Тулью охватывали стоячие, разрезанные сзади поля (кыдыг, бөрттүң кыдыbl) из меха рыси, овцы или ягненка, обычно черного цвета. К макушке тульи пришивали плетеный узел-шишечку дошка, от которого на спину опускались две ленты маак длиной 30-40 см, еще две более широкие ленты тумак прикрепляли к заднему краю тульи.
Состоятельные люди обшивали тулью шелком, а поля делали из шкуры выдры или черного соболя. В сильные морозы вместе с шапкой носили наушники чаактааш, сшитые из шкур ягненка или косули. Подобные головные уборы распространены были и среди бурят. Такие шапки имеют сравнительно позднее происхождение, они появились в период правления Маньчжурской династии Китая в Урянхайском крае [Вайнштейн 1991: 169].

Еще одним свадебным обрядовым действом, символизировавшим переход невесты в категорию замужних, был обряд заплетания кос [Потапов 1969: 246]. По мнению Л. П. Потапова, монгун-тайгинцы не проводят обряд заплетания кос во время свадьбы, их невесты носили две косы с обряда дүгдээшкин [Потапов 1969: 238]. В волосы вплетали искусственные косы чалаа-кара, к середине кос прикрепляли накосное украшение чавага.

Когда жених и невеста были полностью облачены в праздничную одежду, а косы невесты заплетены подобающим образом с украшением чавага, проводился главный обряд, когда жениху давали в зубы кусок вареной нижней губы овцы или барана (хой чырыlbl), а девушку заставляли откусить от этого куска мяса. В это время родители жениха и невесты стояли рядом и наблюдали, удастся ли девушке откусить кусок мяса, который держал в своих зубах жених, по этой примете определяли будущую супружескую жизнь своих детей. После того, как развязывали нитку, которой были связаны руки жениха и невесты, начиналось угощение [Потапов 1969: 246-247].

\section{Заключение}

В традиционном свадебном обряде концентрируется социальный опыт поколений. Результат совершенного в результате свадебного обряда перехода невесты в иное пространство и социальную группу закреплялся внешними выражениями - переплетением кос по-женски и ритуальным обходом молодой вокруг очага в доме мужа, что означало превращение ее в «свою» для членов семьи мужа, его родных, и, конечно, свадебной одеждой, которая меняла ее статус.

Таким образом, свадебные головные уборы тувинцев, особенно у женщин, были 
значимым элементом не только свадебной одежды, но и всей свадебной обрядности в целом, обозначая ее основные этапы в ка-

\section{Полевые материалы авторов}

Байкара Е. Ш. - информант, 1927 г. р., уроженка Пий-Хемского кожууна, консультант, научный сотрудник Национального музея им. «Алдан-Маадыр» Республики Тыва.

Куулар Л. К. - информант, 1955 г. р., уроженка Сут-Хольского кожууна, научный сотрудник Национального музея им. «Алдан-Маадыр» Республики Тыва.

Cam A. B.- информант, 1977 г. р., уроженец c. Кунгуртуг Тере-Хольского района.

\section{Литература}

Антипина 1962 - Антипина К. И. Особенности материальной культуры и прикладного искусства южных киргизов. Фрунзе: Издво Академии наук Киргизской ССР, 1962. $288 \mathrm{c}$.

Богатырев 1971 - Богатырев П. Г. Функции национального костюма в Моравской Словакии // Богатырев П. Г. Вопросы теории народного искусства. М.: Искусство, 1971. С. 297-366.

Вайнштейн 1991 - Вайнштейн С. И. Мир кочевников Центра Азии. М.: Наука, 1991. $294 \mathrm{c}$.

Грумм-Гржимайло 2003 - Грумм-Гржимайло Г. Е. Западная Монголия и Урянхайский край // Традиционная культура тувинцев глазами иностранцев (конец XIX — начало XX в.) / сост. А. К. Кужугет. Кызыл: Тув. кн. изд-во, 2003. С. 108-134.

Дьяконова 1960 - Дьяконова В. П. Материалы по одежде тувинцев (по полевым материа-

\section{References}

Antipina K. I. Southern Kyrgyzes: Peculiarities of Material Culture and Applied Arts Reviewed. Frunze: Kyrgyz SSR Academy of Sciences, 1962. 288 p. (In Russ.)

Bogatyrev P. G. Functions of national costume in Moravian Slovakia. In: Bogatyrev P. G. Theory of Folk Art Exemplified. Moscow: Iskusstvo, 1971. Pp. 297-366. (In Russ.)

Dyakonova V. P. Materials on Tuvan garments: A case study of 1958 field data. In: Scholarly Works of Tuvan Comprehensive Archaeological and Ethnographic Expedition. Vol. I: Materials on Archaeology and Ethnography of Western честве своеобразных маркеров и знаков, символизирующих новые статусы невесты и замужней женщины.

\section{Author's Field Data}

Informant 1: E. Sh. Baikara, b. 1927, native of PiyKhemsky District (Tyva Republic, Russian Federation). Consultant and research associate at Aldan-Maadyr National Museum. (In Tuv. and Russ.)

Informant 2: L. K. Kuular, b. 1955, native of SutKholsky District (Tyva Republic, Russian Federation). Research associate at AldanMaadyr National Museum. (In Tuv. and Russ.) Informant 3: A. V. Sat, b. 1977, native of Kungurtug (Tere-Kholsky District, Tyva Republic, Russia). Rec. in 2019. (In Tuv. and Russ.)

лам 1958 г.) // Труды Тувинской комплексной археолого-этнографической экспедиции. Т. І. Материалы по археологии и этнографии Западной Тувы. М.; Л.: Изд-во АН CCCP, 1960. С. 238-266.

Их Цааз 1981 - Их Цааз («Великое Уложение»). Памятник монгольского феодального права XVII в. / пер. С. Д. Дылыкова. М.: Вост. лит., $1981.148 \mathrm{c}$

Петров 2016 - Петров И. Г. Покрывало невесты в свадебной обрядности чувашей: функции и семантика // Известия Уфимского научного центра РАН. 2016. № 4. С. 110-114.

Потапов 1969 - Потапов Л. П. Очерки народного быта тувинцев. М.: Наука, 1969. 402 с.

Сиянбиль, Сиянбиль 2000 - Сиянбиль М. O., Сиянбиль $A$. A. Традиционный тувинский костюм. Кызыл: Тув. кн. изд-во, 2000. 320 с.

Традиционная культура 2003 - Традиционная культура тувинцев глазами иностранцев (конец XIX - начало XX в.) / сост. А. К. Кужугет. Кызыл: Тув. кн. изд-во, 2003. 225 с.

Tuva. Moscow; Leningrad: USSR Academy of Sciences, 1960. Pp. 238-266. (In Russ.)

Grum-Grshimailo G. E. Northwestern Mongoliya and Uriankhai Land. In: Kuzhuget A. K. (comp.) Tuvan Traditional Culture in Foreign Eyes, Late $19^{\text {th }}-$ Early $20^{\text {th }}$ Centuries. Kyzyl: Tuva Book Publ., 2003. Pp. 108-134. (In Russ.)

Ikh Tsaaz (The Great Code of Laws): $17^{\text {th }}$-Century Monument of Mongolian Feudal Law. S. Dylykov (transl.). Moscow: Vostochnaya Literatura, 1981. 148 p. (In Russ.)

Kuzhuget A. K. (comp.) Tuvan Traditional Culture in Foreign Eyes, Late $19^{\text {th }}$ - Early 
$20^{\text {th }}$ Centuries. Kyzyl: Tuva Book Publ., 2003. 225 p. (In Russ.)

Petrov I. G. Bridal veil in the wedding tradition of the Chuvashes: Functions and semantics. Izvestia Ufimskogo Nauchnogo Tsentra RAN (Proceedings of the RAS Ufa Scientific Centre). 2016. No. 4. Pp. 110-114. (In Russ.)

Potapov L. P. Essays on Tuvan Traditional
Household Life. Moscow: Nauka, 1969. 402 p. (In Russ.)

Siyanbil M. O., Siyanbil A. A. Traditional Tuvan Costume. Kyzyl: Tuva Book Publ., 2000. 320 p. (In Russ.)

Vainshtein S. I. The World of Central Asian Nomads. Moscow: Nauka, 1991. 294 p. (In Russ.) 